\title{
Behavioral and Psychosocial Correlates of Anal Sex Among Male Clients of Female Sex Workers in Tijuana, Mexico
}

\author{
Shirley J. Semple • Steffanie A. Strathdee • \\ Eileen V. Pitpitan · Claudia Chavarin · \\ Thomas L. Patterson
}

Received: 20 May 2014 / Revised: 22 January 2015 / Accepted: 22 January 2015 / Published online: 21 March 2015

(C) Springer Science+Business Media New York 2015

\begin{abstract}
Most studies of heterosexual sex risk practices have focused on condomless vaginal sex despite evidence that condomless anal sex has a significantly higher risk of HIV transmission. The present study focused on male clients' anal sex practices with female sex workers (FSWs) in Tijuana, Mexico, where an HIV epidemic is growing among high-risk groups. Logistic regression analyses were used to identify psychosocial and behavioral correlates of anal sex among male clients. Our sample of HIV-negative men $(N=400)$ was predominantly Latino $(87.5 \%)$, born in Mexico $(78.8 \%)$, never married $(36.8 \%)$ or in a regular or common-law marriage (31.5\%), and employed $(62.8 \%)$, with an average age and education of 37.8 and 9.2 years, respectively. Eighty-nine percent identified as heterosexual and $11 \%$ as bisexual. By design, $50 \%$ of the sample resided in Tijuana and the other $50 \%$ in San Diego County. Nearly half $(49 \%)$ reported at least one incident of anal sex with a FSW in Tijuana in the past 4 months; of those participants, $85 \%$ reported that one or more of their anal sex acts with FSWs had been without a condom. In a multivariate model, anal sex with a FSW in the past 4 months was associated with bisexual identification, methamphetamine use with FSWs, repeat visits to the same FSW, higher scores on perceived stigma about being a client of FSWs, and sexual compulsivity. Prevention programs are needed that address the behavioral and psychosocial correlates of heterosexual
\end{abstract}

S. J. Semple · C. Chavarin · T. L. Patterson ( $₫)$

Department of Psychiatry, University of California, San Diego, 9500 Gilman Drive, Mail Code 0680, La Jolla, CA 92093-0680, USA

e-mail: tpatterson@ucsd.edu

S. A. Strathdee · E. V. Pitpitan

Division of Global Public Health, Department of Medicine,

University of California, San Diego, La Jolla, CA, USA anal sex in order to reduce HIV/STI transmission risk among male clients, FSWs, and their sexual network members.

Keywords Sex workers · Clients of sex workers . Anal sex $\cdot$ HIV and STI risk practices $\cdot$ Mexico . HIV prevention

\section{Introduction}

Mexican cities along the U.S. border are experiencing a growing HIV epidemic that is concentrated among such high-risk groups as female sex workers (FSWs), men who have sex with men (MSM), and injection drug users (Iniguez-Stevens et al., 2009; Strathdee \& Magis-Rodriguez, 2008; Strathdee, MagisRodriguez, Mays, Jimenez, \& Patterson, 2012). To date, little attention has been paid to the role of male clients of FSWs in the spread of HIV/STIs in the region. In a recent study of male clients in Tijuana, $4 \%$ were HIV-infected, and $50 \%$ had had condomless vaginal or anal sex with a FSW in the past 4 months (Goldenberg et al., 2010; Patterson et al., 2009). The extent to which male clients engage in anal sex with FSWs in Tijuana has not been examined separately from vaginal sex, and the correlates of anal sex in this subgroup are unknown.

Most studies of heterosexual risk practices, including those of male clients of FSWs, have focused on condomless vaginal sex (Risser, Padgett, Wolverton, \& Risser, 2009), despite evidence that anal sex without a condom has a significantly higher risk of HIV transmission (Halperin, 1999; Varghese, Maher, Peterman, Branson, \& Steketee, 2002; Voeller, 1991). Anal sex also carries increased risk for contracting rectal gonorrhea, chlamydia, herpes simplex virus, human papilloma virus (HPV), hepatitis B, and syphilis (McBride \& Fortenberry, 2010; Topping et al., 2011). The risks associated with heterosexual anal sex are 
exacerbated by low rates of condom use among heterosexual men and women (Gorbach et al., 2009a; Leichliter, Chandra, Liddon, Fenton, \& Aral, 2007; Lescano et al., 2009; Maynard, Carballo-Dieguez, Ventuneac, Exner, \& Mayer, 2009; Tian et al., 2008). In a U.S. sample, $63 \%$ of heterosexual men and women reported never using condoms for anal sex (Tian et al., 2008). Other studies show that anywhere from 50 to $84 \%$ of men and women engaging in heterosexual anal sex report that they use condoms inconsistently (Gorbach et al., 2009a; Roye, Krauss, \& Silverman, 2010; Tian et al., 2008; Yarber, Graham, Sanders, \& Crosby, 2004). Moreover, using condoms for anal sex carries its own special risks: condoms break and slip off more often during anal sex than they do during vaginal sex (McBride \& Fortenberry, 2010; Silverman \& Gross, 1997), while delayed application, removal of the condom before completion of the sex act, and use of the same condom when switching between vaginal and anal sex can further increase the HIV/STI transmission risk (Bradley et al., 2013; Topping et al., 2011).

Several studies have documented an association between anal sex and the exchange of sex for money or drugs (Gorbach et al., 2009a; Javanbakht et al., 2010; Tucker, Krishna, Prabhakar, Panyam, \& Anand, 2012). Studies of FSWs indicate that anal sex is most often initiated by male clients (Tucker et al., 2012) and is more common among men who are substance users (Risser et al., 2009). Studies in the general population suggest that anal sex is increasing in prevalence among heterosexual adults in developed countries (Aral, Patel, Holmes, \& Foxman, 2005; Mosher, Chandra, \& Jones, 2005; Satterwhite et al., 2007). In the U.S., 30-40\% of heterosexual adults report ever having had anal sex (Gorbach et al., 2009a; Mosher et al., 2005; Stulhofer \& Bacak, 2011). Ethnic differences in the prevalence of heterosexual anal sex have been rarely studied. However, in one study, Javanbakht et al. (2010) reported that heterosexuallyidentified Latino males were more likely to engage in anal sex compared to Whites and African Americans. It has also been suggested that heterosexual Latino males may underestimate the risk of HIV/STI transmission associated with anal sex without a condom (Martinez-Donate et al., 2010). Thus, Latino clients of FSWs may act as a bridge from a high-risk to low-risk populations by having condomless anal sex with both FSWs and non-paid sexual partners (Gorbach, Murphy, Weiss, HucksOrtiz, \& Shoptaw, 2009b).

The purpose of this study was to identify psychosocial and behavioral factors associated with anal sex among male clients of FSWs in Tijuana, Mexico. Developing a profile of the "high-risk" client will help to guide the development of HIV/ STI prevention and intervention programs that target clients who are at the greatest risk for acquiring and transmitting HIV/STIs within their sexual networks. The development of such programs has important public health implications for both Mexico and the United States.

\section{Method}

Participants

Our analyses used baseline data gathered from a sample of 400 male clients of Tijuana-based FSWs between September 2010 and October 2012. The clients were enrolled in a sexual risk reduction intervention known as Hombre Seguro ("Safe Men") (Pitpitan et al., 2014), whose development was informed by data from a large-scale survey of this population that was conducted in 2008 (Patterson et al., 2009). Eligible participants were biologically male, at least 18 years of age, HIV-negative, a resident of either Tijuana or San Diego County, and reported having had condomless vaginal or anal sex with a FSW in Tijuana in the previous 4 months. Time-location sampling (Stueve, O’Donnell, Duran, San Doval, \& Blome, 2001) was used to recruit male clients who solicited bar, brothel, and street-based FSWs in the Zona Roja (red light district) of Tijuana. Trained outreach workers approached men in targeted locations to solicit their participation in the study. Clients were also recruited by jaladores (men who procure clients for FSWs), who were paid \$5 U.S. for each eligible client they referred. Participants were paid $\$ 20$ for a 90 -min computer assisted personal interview (CAPI), which covered sociodemographics, substance use, sexual risk behaviors, mood, social cognitive factors, and other factors associated with clients' risk behaviors. Interviews were conducted in either Spanish or English by trained, bilingual, female interviewers. Participants also underwent rapid testing for HIV, syphilis, gonorrhea, and chlamydia with pre- and post-test counseling and point-of-care treatment. The research protocol was reviewed and approved by the UCSD Human Research Protections Program (\#091302) and the Ethics Committee of Tijuana General Hospital.

Our sample of male clients of FSWs was predominantly Latino $(87.5 \%)$, born in Mexico $(78.8 \%)$, never married or in a regular or common-law marriage $(36.8 \%$ and $31.5 \%$, respectively), and employed $(62.8 \%)$. The average age was 37.8 years $(\mathrm{SD}=10.7$, median $=37.0$, range 18-73) and the average years of education was $9.2(\mathrm{SD}=3.4$, median $=9.0$, range $0-20)$. Thirty-eight percent lived alone, and $31 \%$ lived with another adult who was not a sexual partner. Eighty-nine percent selfidentified as heterosexual; $11 \%$ identified as bisexual. Sixtynine percent had at least one child. By design, $50 \%$ of the sample resided in Tijuana and the other $50 \%$ in San Diego County.

\section{Measures}

Demographic characteristics that were assessed included age, education, marital status, sexual orientation, employment status, living situation, and place of residence.

Substance use was defined as the use of alcohol or illicit drugs with FSWs during the past 4 months. Participants were 
presented with a list of 13 drugs (e.g., marijuana, cocaine, crack, ecstasy, methamphetamine, Mexican speedball) and asked how often they had used each with a FSW in the past 4 months. Frequency of use was rated on a scale from 1 (never) to 6 (every day), and responses were recoded as either 1 (does use) or 0 (does not use). Clients were also asked whether they had been intoxicated with alcohol during sex with a FSW at any time in the past 4 months. Responses were coded 1 (yes) or $0(n o)$.

Contextual factors included the types of locations in Tijuana and the strategies that clients used to solicit FSWs' services. Items queried participants' use of jaladores, after-hour clubs, word-of-mouth, street corners, bars, and strip clubs. The practice of engaging the same FSW's sexual services more than once was also assessed. Responses were coded 1 (yes) or 0 (no).

Sexual risk behavior was defined as anal sex with a FSW in Tijuana in the past 4 months. Male clients were asked to report the number of times that they had engaged in anal sex with a FSW in Tijuana during this time frame, and a dichotomous variable was created to represent the occurrence of any such act, coded as 1 (yes) or 0 (no). For purposes of analysis, we defined this item as our dependent variable (DV).

Psychosocial factors were assessed for possible correlation with anal sex. Depressed mood was measured using the 10-item Center for Epidemiologic Studies Depression Scale. Scale items are clinically derived and have undergone extensive reliability and validation testing (alpha $=0.78)$ (Radloff, 1977). Anxiety and hostility symptoms were measured using subscales of the Brief Symptom Inventory (BSI) (Derogatis \& Melisaratos, 1983). Participants were asked 11 questions to assess anxiety symptoms $($ alpha $=0.87)$ and hostility symptoms (al$\mathrm{pha}=0.84$ ). Items were rated on a scale ranging from 0 (not at all) to 5 (extremely). The 10-item UCLA Loneliness Scale was used to measure feelings of loneliness or social isolation. Items were measured on a scale ranging from 1 (Ineverfeel this way) to 4(Ioftenfeel this way) $($ alpha $=0.93)$ (Russell, Peplau, \& Cutrona, 1980). Attitudes toward male sexuality were assessed using 24 items from the Stereotypes About Male Sexuality Scale (SAMSS) (Snell, Hawkins, \& Belk, 1990), which measures participants' agreement or disagreement with certain stereotypic beliefs about males and their sexuality. Response categories ranged from 1 (disagree) to 5 (agree) $($ alpha $=0.87)$. Sexual compulsivity was measured using a 10-item scale that assesses "obsessive preoccupations with sexual acts and encounters" (Kalichman \& Rompa, 1995). Scores on items ranged from 1 (not at all like me) to 4 (very much like me) $($ alpha $=0.86)$. The 6-item Misogyny scale measured dislike or strong prejudice against women simply because they are female (e.g., "Women are only good for one thing, and that is sex"). Items were rated on a scale from 1 (strongly disagree) to 4 (strongly agree) $($ alpha $=0.71)$. The scales for perceived stigma surrounding being a male client of FSWs and for guilt were developed for use in this research. The 3-item Stigma scale measures the extent to which the client believes that his interactions with FSWs are associated with discrimination, ostracism, and mistreatment by others (e.g., "Most people look down on men who go to prostitutes"). Items were rated on a scale from 1 (strongly disagree) to 4 (strongly agree) (alpha = 0.78). Clients' guilt feelings surrounding their use of FSWs' services were assessed using a 7-item scale (e.g., "I feel guilty about having sex with prostitutes"). Response categories ranged from 1 (strongly disagree) to 4 (strongly agree) $($ alpha $=0.76)$. (For details of the Misogyny, Guilt, and Stigma scales, see "Appendix" section.)

\section{Statistical Analyses}

Statistical analyses compared clients who reported anal sex with a FSW in Tijuana in the past 4 months with those who did not. $t$ tests and contingency-table analysis were used to examine group differences in continuous and categorical variables, respectively. Univariate logistic regressions were used to examine the associations between correlates (IVs) and anal sex with a FSW in the past 4 months (DV). A multivariate logistic regression was used to identify factors independently associated with anal sex with FSWs. Variables that were significant at the $5 \%$ level in univariate logistic regressions were considered for inclusion in the multivariate model.

\section{Results}

Nearly half (49\%) of the sample reported having had anal sex with a FSW in Tijuana in the past 4 months $(\mathrm{n}=196)$. Of those, $85 \%$ reported that at least one of their anal sex acts with FSWs during this time period was condomless. The average number of condomless anal sex acts with FSWs in the past 4 months among the anal-sex group was $4.0(S D=6.28$, median $=2.0$, range $0-50$ ). The average number of condomless vaginal sex acts with FSWs in the past 4 months among this group was 5.7 $(\mathrm{SD}=13.9$, median $=2.0$, range $0-190)$. Twenty-five percent of this group reported ever having had anal or oral sex with another male. Men in this group had significantly more years of education $(9.5$ vs. $8.9, t=1.96, p<.05)$ and were more likely to self-identify as bisexual $\left(16.3 \%\right.$ vs. $\left.6.4, \chi^{2}=10.3, p<.01\right)$ than were men in the non-anal sex group. Table 1 compares background characteristics, contexts of clients' solicitations of sex from FSWs, and substance-use characteristics of the two groups, while Table 2 compares scores on psychosocial factors.

\section{Univariate Logistic Regressions}

Table 3 shows the results of univariate logistic regressions that examined associations between independent variables (psychosocial and behavioral correlates) and the dependent variable (anal sex with a FSW in the past 4 months). Compared to clients who did not have anal sex with FSWs, clients who had 
Table 1 Background characteristics, contexts of sex work solicitation, and substance use practices with FSWs

\begin{tabular}{|c|c|c|}
\hline & \multicolumn{2}{|c|}{$\begin{array}{l}\text { Had anal sex with a FSW } \\
\text { in past } 4 \text { months? }\end{array}$} \\
\hline & $\begin{array}{l}\text { Yes } \\
(N=196) \\
N(\%)\end{array}$ & $\begin{array}{l}\text { No } \\
(N=204) \\
N(\%)\end{array}$ \\
\hline \multicolumn{3}{|l|}{ Background characteristics } \\
\hline Born in United States & $47(24.0)$ & $35(17.2)$ \\
\hline Born in Mexico & $149(76.0)$ & $166(81.4)$ \\
\hline Hispanic or Latino & $172(87.8)$ & $178(87.3)$ \\
\hline Speaks Spanish (vs. does not speak Spanish) & $182(92.9)$ & $191(93.6)$ \\
\hline Speaks English (vs. does not speak English) & $137(69.9)$ & $141(69.1)$ \\
\hline Lives in Tijuana (vs. United States) & $97(49.5)$ & $106(52.0)$ \\
\hline Mean age $(S D)$ & $37.4(10.4)$ & $38.1(11.1)$ \\
\hline $\begin{array}{l}\text { Sexual orientation (bisexual vs. } \\
\text { heterosexual)** }\end{array}$ & $32(16.3)$ & $13(6.4)$ \\
\hline $\begin{array}{l}\text { Married or common-law (vs. other marital } \\
\text { status) }\end{array}$ & $67(34.2)$ & $59(28.9)$ \\
\hline Mean years of education* $(S D)$ & $9.5(3.4)$ & $8.9(3.3)$ \\
\hline Employed (vs. not employed) & $132(67.3)$ & $119(58.3)$ \\
\hline \multicolumn{3}{|l|}{ Contexts for soliciting a FSW in Tijuana ${ }^{a}$} \\
\hline Used jalador** & $23(11.7)$ & $8(3.9)$ \\
\hline Used an after-hours club*** & $58(29.6)$ & $32(15.7)$ \\
\hline Used "word-of-mouth"*** & $42(21.4)$ & $17(8.3)$ \\
\hline Used street corner & $160(81.6)$ & $166(81.4)$ \\
\hline Used a bar & $127(64.8)$ & $129(63.2)$ \\
\hline Used a strip club & $114(58.2)$ & $109(53.4)$ \\
\hline Used the same FSW*** & $109(55.6)$ & $59(28.9)$ \\
\hline \multicolumn{3}{|l|}{ Substance use with a FSW in Tijuana ${ }^{a}$} \\
\hline Marijuana* & $81(41.3)$ & $65(31.9)$ \\
\hline Heroin & $35(17.9)$ & $29(14.2)$ \\
\hline Methamphetamine $* * *$ & $121(61.7)$ & $82(40.2)$ \\
\hline Cocaine* & $44(22.4)$ & $31(15.2)$ \\
\hline Ecstasy & $3(1.5)$ & $1(0.5)$ \\
\hline Amyl nitrates (“poppers") & $2(1.0)$ & $0(0.0)$ \\
\hline Speedball (heroin and cocaine) & $13(6.6)$ & $11(5.4)$ \\
\hline $\begin{array}{l}\text { Mexican speedball (heroin and } \\
\text { methamphetamine) }\end{array}$ & $28(14.3)$ & $22(10.8)$ \\
\hline "Drunk" during sex & $122(62.2)$ & $112(54.9)$ \\
\hline
\end{tabular}

anal sex had greater odds of self-identifying as bisexual (OR 2.87; 95\% CI 1.46-5.65), returning to the same FSW in a 4-month period (OR 3.08; $95 \%$ CI 2.04-4.66), and reporting using the following ways to meet FSWs: jaladores (OR 3.26; $95 \%$ CI 1.42-7.47), after-hours clubs (OR 2.26; $95 \%$ CI 1.393.67), and "word-of-mouth" (OR 3.01; $95 \%$ CI 1.64-5.48). Clients who had anal sex also had greater odds of having used the following substances with a FSW in the past 4 months: marijuana (OR 1.51;95\% CI 1.01-2.27) and methamphetamine (OR 2.40; $95 \%$ CI 1.61-3.59). In addition, men in the anal-sex group had greater odds of obtaining higher scores on perceived client stigma (OR 1.62; $95 \%$ CI 1.09-2.40) and sexual compulsivity (OR 2.48; $95 \%$ CI 1.48-4.17) compared to men in the non-anal sex group. No other psychosocial factors were significantly associated with anal sex.

Factors Independently Associated with Anal Sex with Tijuana-based FSWs

In a multivariate model, five factors were independently associated with a male client's having had anal sex with a FSW in Tijuana in the past 4 months. Clients who self-identified as bisexual had two times the odds of having had anal sex with a FSW compared to clients who did not self-identify as bisexual (AOR $=2.17 ; 95 \%$ CI 1.02-4.59). Also, clients who reported going back to the same FSW had two and one-half times the odds of having had anal sex compared to those who did not return to the same FSW (AOR $=2.59$; $95 \%$ CI 1.65-4.04). Male clients who used methamphetamine with a FSW in the past 4 months had twice the odds of having had anal sex with a FSW (AOR $=2.19 ; 95 \%$ CI 1.37-3.50). Anal sex with FSWs was also associated with perceived stigma of being a client and with sexual compulsivity. For every unit increase in perceived client stigma, the odds of having had anal sex with a FSW almost doubled (AOR $=1.95 ; 95 \%$ CI 1.24-3.08). Similarly, every unit increase in the sexual compulsivity score was associated with almost twice the odds of having had anal sex with a FSW (AOR $=1.91 ; 95 \%$ CI 1.09-3.35) (see Table 3). In a subanalysis, we examined correlates of anal sex without a condom with FSWs by excluding data from the 30 participants who reported anal sex with a condom only. The correlates of condomless anal sex were identical to those reported in the model that compared any anal sex (i.e., with or without a condom) with no anal sex.

\section{Discussion}

This study found a high prevalence of anal sex with FSWs among their male clients in Tijuana, Mexico. Half of our sample reported anal sex with a FSW in the past 4 months, which exceeds estimates for anal sex prevalence in the general heterosexual population of the U.S. (Gorbach et al., 2009b; Javanbakht et al., 2010; Mosher et al., 2005). Moreover, $85 \%$ of clients who had anal sex with FSWs in the past 4 months reported that one or more of those acts was condomless. Factors independently associated with anal sex were bisexual self-identification, using methamphetamine during sex with FSWs, return visits to the same FSW, perceived stigma associated with being a male client, and sexual compulsivity. Our prevalence findings alone suggest that HIV/ STI prevention programs that target male clients of FSWs in the 
Table 2 Mean scores on psychosocial factors

\begin{tabular}{lcc}
\hline & \multicolumn{2}{c}{ Had anal sex with a FSW in past 4 months? } \\
\cline { 2 - 3 } & Yes $(N=196)$ & No $(N=204)$ \\
& M (SD) & M (SD) \\
\hline Depressive symptoms & $9.2(5.0)$ & $8.5(4.7)$ \\
Anxiety symptoms & $10.5(4.9)$ & $9.7(3.7)$ \\
Hostility symptoms & $8.5(4.2)$ & $8.1(3.3)$ \\
Loneliness & $11.0(8.5)$ & $10.5(8.1)$ \\
Traditional male values & $2.7(0.30)$ & $2.7(0.28)$ \\
Misogyny & $13.5(1.7)$ & $13.7(1.1)$ \\
Perceived client stigma* & $2.8(0.48)$ & $2.7(0.53)$ \\
Sexual compulsivity*** & $2.4(0.42)$ & $2.3(0.37)$ \\
Guilt & $2.6(0.42)$ & $2.6(0.34)$ \\
\hline
\end{tabular}

$* p<.05 ; * * * p<.001$

US-Mexico border region should pay greater attention to heterosexual anal sex as a risk behavior. Interventions should aim to educate male clients about the risks of anal sex, promote consistent and proper use of condoms for anal as well as vaginal sex, increase knowledge and awareness of STI symptoms, and advise regular HIV/STI testing.

Male clients who self-identified as bisexual had twice the odds of reporting anal sex with a FSW in the past 4 months. Several other studies have linked bisexual identity and being a man who has sex with both men and women (MSMW) to multiple risks, including anal sex with female partners (Gorbach et al., 2009b; Javanbakht et al., 2010), increased risk for HIV seropositivity compared to men who have sex either exclusively with men or exclusively with women (Martinez-Donate et al., 2010; MunozLaboy \& Dodge, 2007; Prabhu, Owen, Folger, \& McFarland, 2004), and the potential for bridging of HIV/STIs into the heterosexual population (Gorbach et al., 2009b; Hernandez et al., 1992). In Latino culture, factors such as homophobia, stigma, the influence of religious beliefs, and sexual conservatism may prevent bisexual men from being open about their same-sex involvements (Martinez-Donate et al., 2010). In a study in Mexico City, bisexual men had a high prevalence of HIV seropositivity and were more likely to be married and to have a history of sex with FSWs (Hernandez et al., 1992). It has been suggested that Latino MSMW may use substances with opposite-sex partners to reduce anxiety or facilitate sexual interest with women (Martinez-Donate et al., 2010). Also, most Latino MSMW have been found to identify with traditional male heterosexual values (Martinez-Donate et al., 2010), which may make it difficult to interest bisexual Latino male clients of FSWs in HIV/STI prevention programs or recruit them into interventions. Interventions and prevention programs alike need to acknowledge traditional heterosexual self-identity along with hidden same-sex behaviors. Targeted prevention messages should appropriately incorporate cultural beliefs, values, religious influences, and community involvement.
Male clients who reported methamphetamine use during sex with a FSW had twice the odds of reporting anal sex with a FSW in the past 4 months. This finding was consistent with literature that reports a relationship between heterosexual anal sex and the use of methamphetamine by male-female couples. Reynolds, Fisher, Napper, Fremming, and Jansen (2010) found that Latinas who engaged in methamphetamine use in the past 6 months had three times the odds of reporting heterosexual receptive anal sex in the same period. In another study of heterosexuals, methamphetamine use during sex by either or both partners was associated with an increased likelihood of anal sex on those occasions (Zule, Costenbader, Meyer, \& Wechsberg, 2007). Our findings confirmed the interconnectedness of high-risk sex and substance use as reported in other studies of heterosexual risk behavior (Topping et al., 2011). Male clients who use drugs, particularly methamphetamine, are likely to have FSW partners who also use this powerful stimulant (Maher et al., 2011). The co-occurrence of methamphetamine use and anal sex is most likely the explanation for our finding that male clients who had anal sex with a FSW had almost three times the odds of returning to the same FSW compared to clients who did not engage in anal sex. More research is needed to establish whether FSWs' willingness to engage in anal sex with male clients is motivated by increased sexual desire associated with methamphetamine use or whether anal sex with clients facilitates access to this highly addictive drug (Javanbakht et al., 2010).

Male clients with higher client-related stigma scores had about twice the odds of reporting anal sex with a FSW in Tijuana in the past 4 months. Although little is known about stigma associated with transactional sex with FSWs, studies with other populations suggest that men may develop feelings of shame associated with a negative perceptions of what it means to be a client of FSWs (Smolenski, Ross, Risser, \& Rosser, 2009). Clients may also experience loss of reputation or discrimination associated with being seen in the Zona Roja of Tijuana, where solicitations and transactional sex are open to public view. Stigma has also been found to promote secretive behavior (Lieber, Li, Wu, Rotheram-Borus, \& Guan, 2006), which creates a greater challenge for prevention programs and interventions designed to reduce HIV transmission risk behaviors. Stigma associated with going to FSWs may also adversely affect careseeking behaviors of male clients who develop HIV/STI symptoms (Lieber et al., 2006).

Male clients of FSWs may experience stigma from additional sources if they use illicit drugs, are bisexual, or engage in heterosexual anal sex, which despite the gender of the partner is stigmatized by some cultures that consider it to be a male homosexual practice or deviant behavior (Carter, Henry-Moss, Hock-Long, Bergdall, \& Andes, 2010; Halperin, 1999). Male clients who engage in anal sex with FSWs but refuse to disclose or discuss it, particularly with health care professionals, are unlikely to increase their knowledge about the risks of anal sex and thus are likely to persist in their risky practices (Lieber et al., 
Table 3 Univariate and multivariate logistic models examining correlates of anal sex with FSWs

\begin{tabular}{|c|c|c|c|}
\hline & OR & $95 \% \mathrm{CI}$ & $A O R(95 \% \mathrm{CI})$ \\
\hline \multicolumn{4}{|l|}{ Background characteristics } \\
\hline Born in United States (yes vs. no) & 1.52 & $0.93-2.49$ & \\
\hline Hispanic or Latino (vs. other ethnicity) & 1.05 & $0.58-1.89$ & \\
\hline Speaks Spanish (vs. does not speak Spanish) & 0.89 & $0.41-1.93$ & \\
\hline Lives in Tijuana (vs. the United States) & 0.91 & $0.61-1.34$ & \\
\hline Age (per 1 year increase) & 0.99 & $0.98-1.01$ & \\
\hline Sexual orientation (bisexual vs. heterosexual) & $2.87 * *$ & $1.46-5.65$ & $2.17 *(1.02-4.59)$ \\
\hline Married or common-law (vs. other marital status) & 1.28 & $0.84-1.95$ & \\
\hline Years of education (per 1 year increase) & 1.06 & $0.99-1.13$ & \\
\hline Employed (vs. not employed) & 1.47 & $0.98-2.22$ & \\
\hline \multicolumn{4}{|l|}{ Contexts for soliciting a FSW in Tijuana ${ }^{a}$} \\
\hline Used jalador & $3.26 * *$ & $1.42-7.47$ & \\
\hline Used an after hours club & $2.26 * * *$ & $1.39-3.67$ & \\
\hline Used "word-of-mouth" & $3.01 * * *$ & $1.64-5.48$ & \\
\hline Used street corner & 1.02 & $0.61-1.69$ & \\
\hline Used a bar & 1.07 & $0.71-1.61$ & \\
\hline Used a strip club & 1.21 & $0.82-1.80$ & \\
\hline Used the same FSW & $3.08 * * *$ & $2.04-4.66$ & $2.59 * * *(1.65-4.04)$ \\
\hline \multicolumn{4}{|l|}{ Substance use with a FSW in Tijuana ${ }^{a}$} \\
\hline Marijuana & $1.51 *$ & $1.01-2.27$ & \\
\hline Heroin & 1.31 & $0.77-2.24$ & \\
\hline Methamphetamine & $2.40 * * *$ & $1.61-3.59$ & $2.19 * * *(1.37-3.50)$ \\
\hline Cocaine & 1.62 & $0.97-2.69$ & \\
\hline Speedball (heroin and cocaine) & 1.25 & $0.55-2.85$ & \\
\hline Mexican speedball (heroin and methamphetamine) & 1.38 & $0.76-2.50$ & \\
\hline "Drunk" during sex & 1.35 & $0.91-2.02$ & \\
\hline \multicolumn{4}{|l|}{ Psychosocial factors $^{b}$} \\
\hline Depressive symptoms & 1.03 & $0.99-1.07$ & \\
\hline Anxiety symptoms & 1.04 & $0.99-1.09$ & \\
\hline Hostility symptoms & 1.02 & $0.97-1.08$ & \\
\hline Loneliness & 1.01 & $0.98-1.03$ & \\
\hline Traditional male values & 1.92 & $0.96-3.82$ & \\
\hline Misogyny & 0.91 & $0.79-1.04$ & \\
\hline Perceived stigma & $1.62 *$ & $1.09-2.40$ & $1.95 * *(1.24-3.08)$ \\
\hline Sexual compulsivity & $2.48 * * *$ & $1.48-4.17$ & $1.91 *(1.08-3.35)$ \\
\hline Guilt & 1.17 & $0.69-1.96$ & \\
\hline
\end{tabular}

$* p<.05 ; * * p<.01 ; * * * p<.001$

${ }^{\text {a }}$ Recall period is past 4 months

b Odds ratios and adjusted odds ratios are per unit increase

2006). Prevention interventions for male clients of FSWs in Tijuana need to develop culturally appropriate social-cognitive and behavioral strategies for coping with the threat of multiple stigmas faced by male clients.

Sexual compulsivity was associated with almost twice the odds of reporting anal sex with FSWs in the past 4 months. In recent years, literature on sexual compulsivity has burgeoned, focusing primarily on gay and bisexual men. Among the results of these studies are that sexual compulsivity is associated with a number of co-occurring psychosocial and behavioral risk factors, including illicit drug use, polydrug use, methamphetamine use before or during sex, high-risk sexual behavior, depression, childhood sexual abuse, and consumption of pornography (Parsons, Grov, \& Golub, 2012; Parsons, Kelly, Bimbi, Muench, \& 
Morgenstern, 2007; Schwartz, 2008; Semple, Zians, Grant, \& Patterson, 2006). In a recent study, Parsons et al. (2012) found that as the number of psychosocial health problems increased, the odds of engaging in high-risk sexual behaviors, including anal sex, also increased. It was concluded that sexual compulsivity should be addressed as a risk factor that overlaps with other psychosocial health problems to influence HIV/STI risk behaviors. Our data support a similar conclusion.

This research had several limitations. Male clients who volunteered for this study may differ from non-participating clients in being more willing to discuss their sexual practices as well as in the frequency and range of their sexual activities, including anal sex. For these reasons, our sample cannot be considered representative of all male clients of FSWs in Tijuana nor of their counterparts in other cities and countries. Also, some participants' discomfort with the topic of anal sex may have decreased their willingness to report it, resulting in possible underestimation of the prevalence of this risk behavior. The cross-sectional nature of these data further limits our ability to establish causality in the relationships between anal sex and the correlates identified in this study.

The HIV/STI risk profile of male clients of FSWs in Tijuana involves several interrelated psychosocial and behavioral factors. Our findings warrant at least two specific conclusions. First, interventions should target male clients with the highest risk profile so that the maximum number of new HIV/STI infections can be averted. Second, there is a need for comprehensive programs that address the multitude of factors that influence heterosexual anal sex practices. Focusing more public health attention on HIV/STI transmission risks associated with heterosexual anal sex and overcoming barriers to discussing this often secretive sexual practice is imperative for the health of FSWs, male clients of FSWs, and the sexual network members of both populations.

Acknowledgments This research was supported by the National Institute on Drug Abuse, Grant No. R01 DA029008 (T. L. Patterson, P.I.).

\section{Appendix: New Measures*}

\section{Misogyny}

1. In my opinion, women are bad news.

2. Women are only good for one thing, and that is sex.

3. I avoid women except when it comes to sex.

4. It wouldn't bother me to hurt a woman physically.

5. Women have never treated me well.

6. Sex is the only reason why I pursue women.

\section{Stigma}

1. People will treat me differently if they find out that I go to prostitutes.
2. Most people look down on men who go to prostitutes.

3. Most people think that men who go to prostitutes are bad people.

Guilt

1. I feel bad about spending money on prostitutes.

2. Having sex with a prostitute conflicts with my religious beliefs.

3. I feel guilty about having sex with prostitutes.

4. I feel badly for my (wife/steady) when I have sex with a prostitute.

5. I feel guilty if I have unprotected sex with a prostitute.

6. I worry that my (wife/steady partner) will find out about my going to prostitutes.

7. It bothers me that I have a secret life of going to prostitutes.

* Response categories on all these measures ranged from 1 (strongly disagree) to 4 (strongly agree).

\section{References}

Aral, S. O., Patel, D. A., Holmes, K. K., \& Foxman, B. (2005). Temporal trends in sexual behaviors and sexually transmitted disease history among 18- to 39-year-old Seattle, Washington, residents: Results of random digit-dial surveys. Sexually Transmitted Diseases, 32, $710-717$

Bradley, J., Rajaram, S., Moses, S., Gowda, G. C., Pushpalatha, R., Ramesh, B. M., ... Alary, M. (2013). Female sex worker client behaviors lead to condom breakage: A prospective telephone-based survey in Bangalore, South India. AIDS and Behavior, 17, 559-567. doi:10.1007/s10461-012-0192-3.

Carter, M., Henry-Moss, D., Hock-Long, L., Bergdall, A., \& Andes, K. (2010). Heterosexual anal sex experiences among Puerto Rican and Black young adults. Perspectives on Sexual and Reproductive Health, 42, 267-274. doi:10.1363/4226710.

Derogatis, L. R., \& Melisaratos, N. (1983). The Brief Symptom Inventory: An introductory report. Psychological Medicine, 13, 595-605.

Goldenberg, S. M., Gallardo Cruz, M., Strathdee, S. A., Nguyen, L., Semple, S. J., \& Patterson, T. L. (2010). Correlates of unprotected sex with female sex workers among male clients in Tijuana, Mexico. Sexually Transmitted Diseases, 37, 319-324.

Gorbach, P. M., Manhart, L. E., Hess, K. L., Stoner, B. P., Martin, D. H., \& Holmes, K. K. (2009a). Anal intercourse among young heterosexuals in three sexually transmitted disease clinics in the United States. Sexually Transmitted Diseases, 36, 193-198. doi:10.1097/OLQ. 0b013e3181901ccf.

Gorbach, P. M., Murphy, R., Weiss, R. E., Hucks-Ortiz, C., \& Shoptaw, S. (2009b). Bridging sexual boundaries: Men who have sex with men and women in a street-based sample in Los Angeles. Journal of Urban Health, 86(Suppl. 1), 63-76. doi:10.1007/s11524-009-9370-7.

Halperin, D. T. (1999). Heterosexual anal intercourse: Prevalence, cultural factors, and HIV infection and other health risks, part I. AIDS Patient Care and STDs, 13, 717-730.

Hernandez, M., Uribe, P., Gortmaker, S., Avila, C., De Caso, L. E., Mueller, N., \& Sepulveda, J. (1992). Sexual behavior and status for human immunodeficiency virus type 1 among homosexual and bisexual males in Mexico City. American Journal of Epidemiology, $135,883-894$. 
Iniguez-Stevens, E., Brouwer, K. C., Hogg, R. S., Patterson, T. L., Lozada, R., Magis-Rodriguez, C., ... Strathdee, S. A. (2009). Estimating the 2006 prevalence of HIV by gender and risk groups in Tijuana, Mexico. Gaceta Médica de México, 145, 189-195.

Javanbakht, M., Guerry, S., Gorbach, P. M., Stirland, A., Chien, M., Anton, P., \& Kerndt, P. R. (2010). Prevalence and correlates of heterosexual anal intercourse among clients attending public sexually transmitted disease clinics in Los Angeles County. Sexually Transmitted Diseases, 37, 369-376.

Kalichman, S. C., \& Rompa, D. (1995). Sexual sensation seeking and Sexual Compulsivity Scales: Reliability, validity, and predicting HIV risk behavior. Journal of Personality Assessment, 65, 586-601.

Leichliter, J. S., Chandra, A., Liddon, N., Fenton, K. A., \& Aral, S. O. (2007). Prevalence and correlates of heterosexual anal and oral sex in adolescents and adults in the United States. Journal of Infectious Diseases, 196, 1852-1859. doi:10.1086/522867.

Lescano, C. M., Houck, C. D., Brown, L. K., Doherty, G., DiClemente, R. J., Fernandez, M. I., ... Silver, B. J. (2009). Correlates of heterosexual anal intercourse among at-risk adolescents and young adults. American Journal of Public Health, 99, 1131-1136. doi:10. 2105/AJPH.2007.123752.

Lieber, E., Li, L., Wu, Z., Rotheram-Borus, M. J., \& Guan, J. (2006). HIV/ STD stigmatization fears as health-seeking barriers in China. AIDS and Behavior, 10, 463-471. doi:10.1007/s10461-005-9047-5.

Maher, L., Phlong, P., Mooney-Somers, J., Keo, S., Stein, E., Couture, M. C., \& Page, K. (2011). Amphetamine-type stimulant use and HIV/STI risk behaviour among young female sex workers in Phnom Penh, Cambodia. International Journal on Drug Policy, 22, 203-209. doi:10.1016/j.drugpo.2011.01.003.

Martinez-Donate, A. P., Zellner, J. A., Sanudo, F., Fernandez-Cerdeno, A., Hovell, M. F., Sipan, C. L., ... Carrillo, H. (2010). Hombres Sanos: Evaluation of a social marketing campaign for heterosexually identified Latino men who have sex with men and women. American Journal of Public Health, 100, 2532-2540. doi:10.2105/ AJPH.2009.179648.

Maynard, E., Carballo-Dieguez, A., Ventuneac, A., Exner, T., \& Mayer, K. (2009). Women's experiences with anal sex: Motivations and implications for STD prevention. Perspectives on Sexual and Reproductive Health, 41, 142-149. doi:10.1363/4114209.

McBride, K. R., \& Fortenberry, J. D. (2010). Heterosexual anal sexuality and anal sex behaviors: A review. Journal of Sex Research, 47, 123-136. doi:10.1080/00224490903402538.

Mosher, W. D., Chandra, A., \& Jones, J. (2005). Sexual behavior and selected health measures: Men and women 15-44 years of age, United States, 2002. Advance Data, 362, 1-55.

Munoz-Laboy, M., \& Dodge, B. (2007). Bisexual Latino men and HIV and sexually transmitted infections risk: An exploratory analysis. American Journal of Public Health, 97, 1102-1106. doi:10.2105/ AJPH.2005.078345.

Parsons, J. T., Grov, C., \& Golub, S. A. (2012). Sexual compulsivity, cooccurring psychosocial health problems, and HIV risk among gay and bisexual men: Further evidence of a syndemic. American Journal of Public Health, 102, 156-162. doi:10.2105/AJPH.2011. 300284.

Parsons, J. T., Kelly, B. C., Bimbi, D. S., Muench, F., \& Morgenstern, J. (2007). Accounting for the social triggers of sexual compulsivity. Journal of Addictive Diseases, 26, 5-16. doi:10.1300/J069v26n03_ 02.

Patterson, T. L., Goldenberg, S., Gallardo, M., Lozada, R., Semple, S. J., Orozovich, P., ... Strathdee, S. A. (2009). Correlates of HIV, sexually transmitted infections, and associated high-risk behaviors among male clients of female sex workers in Tijuana, Mexico. AIDS, 23, 1765-1771.

Pitpitan, E. V., Chavarin, C. V., Semple, S. J., Magis-Rodriguez, C., Strathdee, S. A., \& Patterson, T. L. (2014). Hombre Seguro (Safe Men): A sexual risk reduction intervention for male clients of female sex workers. BMC Public Health, 14, 475. doi:10.1186/ 1471-2458-14-475.

Prabhu, R., Owen, C. L., Folger, K., \& McFarland, W. (2004). The bisexual bridge revisited: Sexual risk behavior among men who have sex with men and women, San Francisco, 1998-2003. AIDS, 18, 1604-1606.

Radloff, L. S. (1977). The CES-D Scale: A self-report depression scale for research in the general population. Applied Psychological Measurement, 1, 385-401.

Reynolds, G. L., Fisher, D. G., Napper, L. E., Fremming, B. W., \& Jansen, M. A. (2010). Heterosexual anal sex reported by women receiving HIV prevention services in Los Angeles County. Women's Health Issues, 20, 414-419. doi:10.1016/j.whi.2010.07.006.

Risser, J. M., Padgett, P., Wolverton, M., \& Risser, W. L. (2009). Relationship between heterosexual anal sex, injection drug use and HIV infection among Black men and women. International Journal of STD and AIDS, 20, 310-314. doi:10.1258/ijsa.2008.008394.

Roye, C. F., Krauss, B. J., \& Silverman, P. L. (2010). Prevalence and correlates of heterosexual anal intercourse among Black and Latina female adolescents. Journal of the Association of Nurses in AIDS Care, 21, 291-301. doi:10.1016/j.jana.2009.12.002.

Russell, D., Peplau, L. A., \& Cutrona, C. E. (1980). The revised UCLA Loneliness Scale: Concurrent and discriminant validity evidence. Journal of Personality and Social Psychology, 39, 472-480.

Satterwhite, C. L., Kamb, M. L., Metcalf, C., Douglas, J. M., Malotte, C. K., Paul, S., \& Peterman, T. A. (2007). Changes in sexual behavior and STD prevalence among heterosexual STD clinic attendees: 1993-1995 versus 1999-2000. Sexually Transmitted Diseases, 34, 815-819. doi:10.1097/OLQ.0b013e31805c751d.

Schwartz, M. F. (2008). Developmental psychopathological perspectives on sexually compulsive behavior. Psychiatric Clinics of North America, 31, 567-586. doi:10.1016/j.psc.2008.07.002.

Semple, S. J., Zians, J., Grant, I., \& Patterson, T. L. (2006). Sexual compulsivity in a sample of HIV-positive methamphetamine-using gay and bisexual men. AIDS and Behavior, 10, 587-598. doi:10. 1007/s10461-006-9127-1.

Silverman, B. G., \& Gross, T. P. (1997). Use and effectiveness of condoms during anal intercourse: A review. Sexually Transmitted Diseases, 24, 11-17.

Smolenski, D. J., Ross, M. W., Risser, J. M., \& Rosser, B. R. (2009). Sexual compulsivity and high-risk sex among Latino men: The role of internalized homonegativity and gay organizations. AIDS Care, 21, 42-49. doi:10.1080/09540120802068803.

Snell, W. E., Hawkins, R. C., \& Belk, S. (1990). Stereotypes about male sexuality and the use of social influence strategies in intimate relationships. Journal of Social and Clinical Psychology, 7 , $42-48$.

Strathdee, S. A., \& Magis-Rodriguez, C. (2008). Mexico's evolving HIV epidemic. Journal of the American Medical Association, 300, 571573.

Strathdee, S. A., Magis-Rodriguez, C., Mays, V. M., Jimenez, R., \& Patterson, T. L. (2012). The emerging HIV epidemic on the Mexico-U.S. border: An international case study characterizing the role of epidemiology in surveillance and response. Annals of Epidemiology, 22, 426-438. doi:10.1016/j.annepidem.2012.04.002.

Stueve, A., O’Donnell, L. N., Duran, R., San Doval, A., \& Blome, J. (2001). Time-space sampling in minority communities: Results with young Latino men who have sex with men. American Journal of Public Health, 91, 922-926.

Stulhofer, A., \& Bacak, V. (2011). Is anal sex a marker for sexual risktaking? Results from a population-based study of young Croatian adults. Sexual Health, 8, 384-389. doi:10.1071/SH10078.

Tian, L. H., Peterman, T. A., Tao, G., Brooks, L. C., Metcalf, C., Malotte, C. K., ... Douglas, J. M. (2008). Heterosexual anal sex activity in the year after an STD clinic visit. Sexually Transmitted Diseases, 35, 905-909. doi:10.1097/OLQ.0b013e318181294b. 
Topping, A. A., Milhausen, R. R., Graham, C. A., Sanders, S. A., Yarber, W. L., \& Crosby, R. A. (2011). A comparison of condom use errors and problems for heterosexual anal and vaginal intercourse. International Journal of STD and AIDS, 22, 204-208. doi:10.1258/ijsa.2011. 010259.

Tucker, S., Krishna, R., Prabhakar, P., Panyam, S., \& Anand, P. (2012). Exploring dynamics of anal sex among female sex workers in Andhra Pradesh. Indian Journal of Sexually Transmitted Diseases, 33, 9-15. doi:10.4103/0253-7184.93787.

Varghese, B., Maher, J. E., Peterman, T. A., Branson, B. M., \& Steketee, R. W. (2002). Reducing the risk of sexual HIV transmission: Quantifying the per-act risk for HIV on the basis of choice of partner, sex act, and condom use. Sexually Transmitted Diseases, 29, 38-43.
Voeller, B. (1991). AIDS and heterosexual anal intercourse. Archives of Sexual Behavior, 20, 233-276.

Yarber, W. L., Graham, C. A., Sanders, S. A., \& Crosby, R. A. (2004). Correlates of condom breakage and slippage among university undergraduates. International Journal of STD and AIDS, 15, 467-472. doi:10.1258/0956462041211207.

Zule, W. A., Costenbader, E. C., Meyer, W. J., \& Wechsberg, W. M. (2007). Methamphetamine use and risky sexual behaviors during heterosexual encounters. Sexually Transmitted Diseases, 34, 689694. doi:10.1097/01.olq.0000260949.35304.22. 